\title{
Separation of waste plastic resulting from electrical products by forced aeration flotation
}

\author{
Cristina GHINEA and Sergiu PADURET*
}

Stefan cel Mare University of Suceava, Faculty of Food Engineering, 13 Universitatii Street, 720229 Suceava, Romania

\begin{abstract}
The separation of four waste plastic samples - Polyvinyl chloride (PVC), Acrylonitrile butadiene styrene (ABS), Polycarbonates (PC), and Polyamides (PA) resulting from electrical products in three bicomponent plastic mixtures (PVC-ABS, PVC - PA, and PVC - PC) was performed by using four different flotation solutions $(5 \%$, 10\%, $20 \%$, and $30 \%$ concentration) of $\mathrm{CaCl}_{2}$. Furthermore, the waste plastic samples were analyzed in terms of density, specific volume, particle size, initial water content, and water absorption capacity, while the flotation solutions were analyzed in terms of $\mathrm{pH}$, density, electrical conductivity, and refractive index. Results showed that from the analyzed waste plastic samples, the PVC sample has the highest density $\left(1.3823 \mathrm{~g} / \mathrm{cm}^{3}\right)$, followed by PC $\left(1.2034 \mathrm{~g} / \mathrm{cm}^{3}\right)$ and PA $\left(1.0607 \mathrm{~g} / \mathrm{cm}^{3}\right)$, while the ABS $\left(0.9723 \mathrm{~g} / \mathrm{cm}^{3}\right)$ presented the lowest value. The highest recovery rate was obtained for the PVC samples $(98.10 \%-99.75 \%)$ when it was mixed with ABS, whereas the highest purity was measured for ABS samples $(98.29 \%$ $-99.76 \%$ ) in the case of the same mixture.
\end{abstract}

Keywords: acrylonitrile butadiene styrene; flotation; polyamides; polycarbonates; PVC; waste plastic.

\section{Introduction}

Plastic is one of the most used materials due to its properties: cheap, versatile, light, and durable [1, 2]. In 2019, 368 million tonnes of plastics were produced worldwide, of which approximately 58 million tonnes were produced in Europe [3]. At the European level, 50.7 million tonnes were demanded, thus: $39.6 \%$ for packaging, $20.4 \%$ for buildings and constructions, $9.6 \%$ for automotive, $6.2 \%$ for electrical and electronic, and $24.2 \%$ for others (households, agriculture, furniture, etc.). According to Plastics Europe [3], polyvinyl chloride (PVC) demand was approximately 5 million tonnes, while acrylonitrile butadiene styrene (ABS), polycarbonates (PC), polyamides (PA) demands were approximately 1 million tonnes for each. The highest demand for PVC comes from the building and construction sector followed by the packaging sector and others. PVC is also used in the electrical and electronic sector, as well as ABS, PC, and PA. After consumption, plastics waste can be recycled, incinerated for energy recovery, or landfilled $[4,5]$. In 2018, at the European level, 29.1 million tonnes of plastic waste were collected, of which $42.6 \%$ were used for energy recovery, $32.5 \%$ were recycled and $24.9 \%$ were landfilled [3]. It is obvious that a high percentage of plastic waste is still landfilled, and in order to achieve the circular economy for plastic, zero landfilling is needed. The degradation of plastic in landfills takes a long time and leads to environmental pollution [1, 2]. However, at the European level, the recycling of plastic waste is on a positive trend. Mechanical recycling of plastics waste includes a few steps like collection (from separate and mixed waste streams), first sorting (separation by the type of materials), shredding (in small pieces), washing, second sorting, and extrusion (homogenous pellets). One of the most important challenges of the plastic waste management system is its separation into plastic types [6,7]. There are different sorting techniques: manual (visual identification), and automatic like dry sorting: IR, X-Rays, air, electrostatic, mechanical and melting; wet sorting: flotation, centrifugal acceleration (hydrocyclons), selective dissolution; chemical sorting: hydrolysis, glycolysis, hydroglycolysis [6]. One of the simplest and cheapest sorting techniques is froth flotation. Plastic recovery through this technique requires wetting and frothing agents. It was considered that hydrophobicity and gravitational force are the main responsible for the separation of plastics by flotation [8]. Al-Salem et al. [9], Ruj et al. [6], and Ragaert et al. [10] stated that flotation is based on a different density of plastics. Plastics have hydrophobic surfaces and according to Ruj et al. [6] the plastic surface should be hydrophilic for at least one type of plastic investigated, in order to separate the plastics. Water is used as a flotation agent and the wetting agents suitable for flotation are tannic acid, methylcellulose, lignosulfonates which increase the plastics surface hydrophilic capacity $[11,12]$. Ethyl alcohol and calcium chloride aqueous solutions were used by Pongstabodee et al. [13] for plastics separation into subgroups based on their density, while Utimura et al. [14] separated plastics from waste electrical and electronic equipment by flotation using ethanol and acetic acid. According to Burat et al. [15], the separation of plastics with similar densities by flotation can be performed through modification of plastics surfaces. In different studies, the plastics surfaces were modified by sodium hydroxide - $\mathrm{NaOH}$ [15-17], ammonia - $\mathrm{NH}_{3}$

*Corresponding author. E-mail address: sergiu.paduret@fia.usv.ro (Sergiu Paduret) 
[18], potassium permanganate - $\mathrm{KMnO}_{4}$ [19], sodium hypochlorite - $\mathrm{NaClO}[20]$, chlorine dioxide - $\mathrm{ClO}_{2}$ [21].

Therefore, this study aimed to evaluate the flotation separation of waste plastic resulting from electrical products in bicomponent plastic mixtures using flotation solutions of different concentrations. The productivity of the separation process was estimated in accordance with the concentrations of flotation solutions by recovery rate and purity measurements.

\section{Experimental}

\subsection{Materials and methods}

Polyvinyl chloride, acrylonitrile butadiene styrene, polycarbonates, polyamides are four different types of plastic, which can be found in plastic waste cables or other electrical products, and were chosen as materials for this study (Figure 1). The sample wastes were provided by two Romanian companies (ECO Recycling CNE, Timisoara and Hidroplasto, Botosani) that deal with plastic recycling. They supplied the plastic by categories, PVC was multicolored (without black), while the other types of plastic were black. All types of plastic waste used in this study are from electrical products. The plastic waste used in this experiment had a size between 0.2 and $0.5 \mathrm{~cm}$.

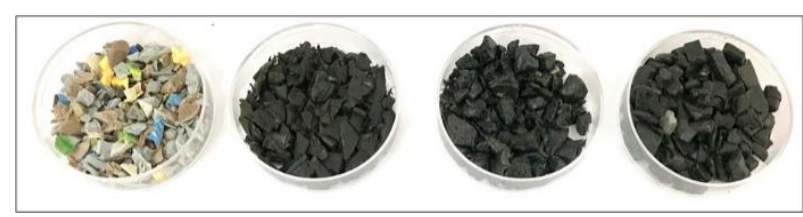

Figure 1. PVC, PA, PC, and ABS plastic waste samples

The analyze of density and specific volume of plastic samples was conducted according to ASTM D-20 2008 [22].

For the determination of water absorption, the plastic samples were dried at $50 \pm 2{ }^{\circ} \mathrm{C}$ to constant mass, cooled in a desiccator, weighed, and then placed in distilled water maintained at $23 \pm 1{ }^{\circ} \mathrm{C}$. The plastic samples were periodically weighed and the results of plastic water absorption (c) were expressed as mass percentages of water absorbed [23].

Distilled water and $\mathrm{CaCl}_{2}$ anhydrous as reagents were used through the experiments. Different solutions of distilled water and $\mathrm{CaCl}_{2}$ with $5 \%, 10 \%, 20 \%$, and $30 \%$ concentration were chosen for the flotation tests.

The $\mathrm{CaCl}_{2}$ solutions were characterized in terms of $\mathrm{pH}$, density, electrical conductivity, and refractive index. The $\mathrm{pH}$ was measured with a Mettler Toledo $\mathrm{pH}$ meter, the conductivity measurements were performed with an XL30 Accumet conductivity meter, while the Leica Mark II Plus refractometer was used for refractive index evaluation. In addition, the density of $\mathrm{CaCl}_{2}$ solutions was also determined according to Viana et al. [24].

All determinations were performed in triplicate. All reagents used in this study were procured from Sigma Aldrich (Germany).

Flotation experiments were carried out in a flotation column with a height of $40 \mathrm{~cm}$ and a diameter of $8 \mathrm{~cm}$ (Figure 2). Polymer particles were weighed, combined, and introduced in the flotation column. There were considered three types of polymer particles combination: PVC with ABS, PVC with PC, and PVC with PA. In each flotation test, the sample used consisted of a mixture of $20 \mathrm{~g}$ plastic. The flotation column was filled with $0.5 \mathrm{~L}$ of flotation solution. Compressed air was introduced in the flotation column and gas bubbles were produced when air passed over a membrane. The airflow rate was $400 \mathrm{~L} / \mathrm{h}$ and a flotation test was conducted for $4 \mathrm{~min}$. After the flotation test plastics waste was collected, rinsed in distilled water, dried in the atmosphere, and weighed.

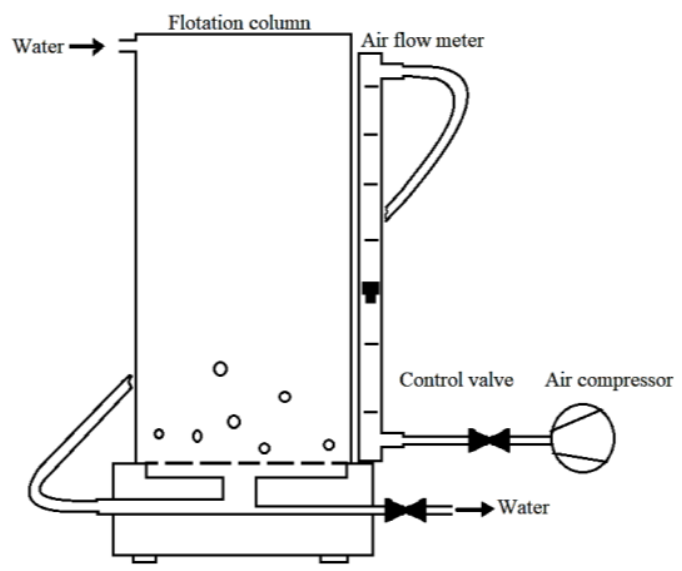

Figure 2. Installation for separating plastic by flotation

Flotation rate can be used to express the flotation behavior of plastics (Eq. 1) [25]:

$$
\text { floating ratio }=\frac{M_{f p}}{M_{f p}+M_{s p}} * 100
$$

where: $M_{\mathrm{fp}}$ represents the mass of floating plastics and $\mathrm{M}_{\mathrm{sp}}$ is the mass of submerged plastics.

The determination of the separation efficiency was performed by calculating the recovery and purity indices (Table 1).

Table 1. Recovery and purity equations used in this study

\begin{tabular}{|c|c|}
\hline Recovery equations & Purity equations \\
\hline $\begin{array}{l}\text { recovery }_{P V C}= \\
\frac{M_{S P V C}}{M_{S P V C}+M_{f P V C}} * 100,(\%)(2)\end{array}$ & $\begin{array}{l}\text { purity }_{P V C}=\frac{M_{S P V C}}{M_{S P V C}+M_{S A B S}} * \\
100,(\%)\end{array}$ \\
\hline $\begin{array}{l}\text { recovery }_{A B S}= \\
\frac{M_{f A B S}}{M_{f A B S}+M_{S A B S}} * 100,(\%)\end{array}$ & $\begin{array}{l}\text { purity }_{A B S}=\frac{M_{f A B S}}{M_{f A B S}+M_{f P V C}} * \\
100,(\%) \quad(7)\end{array}$ \\
\hline $\begin{array}{l}\text { recovery }_{P C}=\frac{M_{f P C}}{M_{f P C}+M_{S P C}} * \\
100,(\%)\end{array}$ & $\begin{array}{l}\text { purity }_{P V C}=\frac{M_{S P V C}}{M_{S P V C}+M_{S P C}} * 100, \\
(\%) \quad(8) \\
\text { purity }_{P C}=\frac{M_{f P C}}{M_{f P C}+M_{f P V C}} * 100, \\
(\%) \quad(9)\end{array}$ \\
\hline $\begin{array}{l}\text { recovery }_{P A}=\frac{M_{f P A}}{M_{f P A}+M_{S P A}} * \\
100,(\%)\end{array}$ & $\begin{array}{l}\text { purity }_{P V C}=\frac{M_{S P V C}}{M_{S P V C}+M_{S P A}} * 100, \\
(\%) \quad(10) \\
\text { purity }_{P A}=\frac{M_{f P A}}{M_{f P A}+M_{f P V C}} * 100, \\
(\%) \quad(11)\end{array}$ \\
\hline
\end{tabular}

where: $\mathrm{M}_{\mathrm{SPVC}}, \mathrm{M}_{\mathrm{SABS}}, \mathrm{M}_{\mathrm{SPA}}, \mathrm{M}_{\mathrm{sPC}}$ are the mass of PVC, ABS, PA and $\mathrm{PC}$ in the submerged products, while $\mathrm{M}_{\mathrm{fPVC}}, \mathrm{M}_{\mathrm{fABS}}, \mathrm{M}_{\mathrm{fPA}}, \mathrm{M}_{\mathrm{fPC}}$ are the mass of PVC, ABS, PA and PC in the floating products.

\subsection{Statistical analysis}

The measured values were used for the ANOVA analysis of variance, performed with STATGRAPHICS CENTURION XVI software (Trial Version), and for Pearson correlation performed with SPSS 13.0 software (SPSS Inc. Chicago, IL). 


\section{Results and discussion}

\subsection{Characterization of waste plastics and flotation solution}

The density and specific volume of the waste plastics were determined and presented in Table 2 . It can be observed that PVC density is higher than the densities of the other plastic types (ABS, PC, PA) considered in this study. The ANOVA analysis divided the density and specific volume results into different statistical groups $\left({ }^{\text {a-d }}\right)$.

The PVC was the submerged plastic due to its higher density, while the other plastics floated. The densities of the plastic types considered in this study have values similar to those found in other studies published as follows: PVC 1.19-1.54 g/cm 3 , ABS $1.02-1.21 \mathrm{~g} / \mathrm{cm}^{3}$, PC $1.20-1.22 \mathrm{~g} / \mathrm{cm}^{3}$, PA $1.01-1.20 \mathrm{~g} / \mathrm{cm}^{3}$ [2, 13, 26-28].

In the recycling process of waste plastics, the moisture content represents a significant characteristic that impacts the decisions for transportation, treatment procedures, and also influences the reuse condition [29]. The initial moisture content of waste polymers ranged between $0.0345 \%\left({ }^{\mathrm{d}}\right)$ and $1.0053 \%\left({ }^{\mathrm{a}}\right)$ the highest value being measured for PA samples, while the PVC samples presented the lowest results.

The ANOVA statistics highlighted the difference between the physical properties of analyzed waste polymers at a level of $\mathrm{p}<0.001$, which indicates that the plastic samples used in the present study have different properties.

Table 2. Physical properties of waste polymers used in flotation tests

\begin{tabular}{|l|c|c|c|}
\hline \multicolumn{1}{|c|}{ Polymer } & $\begin{array}{c}\text { Density } \\
\left(\mathbf{g} / \mathbf{c m}^{\mathbf{3}}\right)\end{array}$ & $\begin{array}{c}\text { Specific volume } \\
\left(\mathbf{c m}^{\mathbf{3} / \mathbf{g})}\right.\end{array}$ & $\begin{array}{c}\text { Moisture content } \\
(\mathbf{\%})\end{array}$ \\
\hline PVC & $1.3823^{\mathrm{a}} \pm 0.0006$ & $0.7234^{\mathrm{d}} \pm 0.0003$ & $0.0345^{\mathrm{d}} \pm 0.0048$ \\
\hline ABS & $0.9723^{\mathrm{d}} \pm 0.0019$ & $1.0284^{\mathrm{a}} \pm 0.0020$ & $0.1918^{\mathrm{b}} \pm 0.0017$ \\
\hline PC & $1.2034^{\mathrm{b}} \pm 0.0060$ & $0.8312^{\mathrm{c}} \pm 0.0043$ & $0.0864^{\mathrm{c}} \pm 0.0156$ \\
\hline PA & $1.0607^{\mathrm{c}} \pm 0.0025$ & $0.9427^{\mathrm{b}} \pm 0.0022$ & $1.0053^{\mathrm{a}} \pm 0.0031$ \\
\hline F-Ratio & 8127 & 7599 & 5912 \\
\hline P- Value & $\mathrm{p}<0.001$ & $\mathrm{p}<0.001$ & $\mathrm{p}<0.001$ \\
\hline
\end{tabular}

Different lowercase letters $(a-d)$ in a column show significant differences between the groups $(p<0.05)$.

Density, $\mathrm{pH}$, electrical conductivity, and refractive index determined for each $\mathrm{CaCl}_{2}$ solution are presented in Table 3. The $\mathrm{pH}$ values of the $\mathrm{CaCl}_{2}$ solutions decreased with the increase of the solution concentration from 6.84 at $5 \%$ to 6.27 at $30 \%$; the ANOVA analysis highlighted this difference at a level of $\mathrm{p}<0.001$. These values indicating a weakly acidic to neutral $\mathrm{pH}$. The $\mathrm{pH}$ of the solution used for flotation is also an important issue, especially when, after utilization, it is sent to a wastewater treatment plant. Densities and electrical conductivities of $\mathrm{CaCl}_{2}$ solution increased with the increase of the concentration from 1.0358 to 1.2282 $\mathrm{g} / \mathrm{cm}^{3}$ and from 58.66 to $168.66 \mathrm{mS} / \mathrm{cm}$ respectively.

Based on the analysis of variance ANOVA it can be observed that the results of density, electrical conductivity, and refractive index are distributed in the same statistical group $\left({ }^{a}-d\right)$ in accordance with the flotation solutions concentration.

Table 3. Characterization of $\mathrm{CaCl}_{2}$ solution used in flotation tests

\begin{tabular}{|c|c|c|c|c|}
\hline $\begin{array}{c}\mathbf{C a C l}_{2} \text { concentration } \\
(\mathbf{\%})\end{array}$ & $\mathbf{p H}$ & $\begin{array}{c}\text { Density } \\
\left(\mathbf{g} / \mathbf{c m}^{\mathbf{3}}\right)\end{array}$ & $\begin{array}{c}\text { Electrical conductivity } \\
(\mathbf{m S} / \mathbf{c m})\end{array}$ & Refractive index \\
\hline 5 & $6.8466^{\mathrm{a}} \pm 0.0047$ & $1.0358^{\mathrm{d}} \pm 0.0001$ & $58.66^{\mathrm{d}} \pm 0.2011$ & $1.3435^{\mathrm{d}} \pm 0.0001$ \\
\hline 10 & $6.7500^{\mathrm{b}} \pm 0.0081$ & $1.0742^{\mathrm{c}} \pm 0.0001$ & $101.033^{\mathrm{c}} \pm 0.2494$ & $1.3541^{\mathrm{c}} \pm 0.0002$ \\
\hline 20 & $6.4000^{\mathrm{c}} \pm 0.0141$ & $1.1432^{\mathrm{b}} \pm 0.0001$ & $151.26^{\mathrm{b}} \pm 0.3681$ & $1.3751^{\mathrm{b}} \pm 0.0002$ \\
\hline 30 & $6.2733^{\mathrm{d}} \pm 0.0094$ & $1.2282^{\mathrm{a}} \pm 0.0001$ & $168.66^{\mathrm{a}} \pm 0.0471$ & $1.3977^{\mathrm{a}} \pm 0.0001$ \\
\hline F-Ratio & 1594 & 2200491 & 82820 & 25570 \\
\hline p- Value & $\mathrm{p}<0.001$ & $\mathrm{p}<0.001$ & $\mathrm{p}<0.001$ & $\mathrm{p}<0.001$ \\
\hline
\end{tabular}

Different lowercase letters $(\mathrm{a}-\mathrm{d})$ in a row show significant differences between the groups $(\mathrm{p}<0.05)$.

In Figure 3 is presented the water absorption of PA, PVC, ABS, and PC plastic samples immersed in distilled water for 24, 48, 72, 96, 120, and 192 hours. It can be observed that the highest water absorption was measured for PA samples, which varied from $2.641 \%$ to $6.263 \%$. The other analyzed samples showed close values at the beginning $(0.219 \% \mathrm{PVC}, 0.378 \% \mathrm{ABS}$, and $0.165 \% \mathrm{PC}$ ), but during the measurements there were variations.

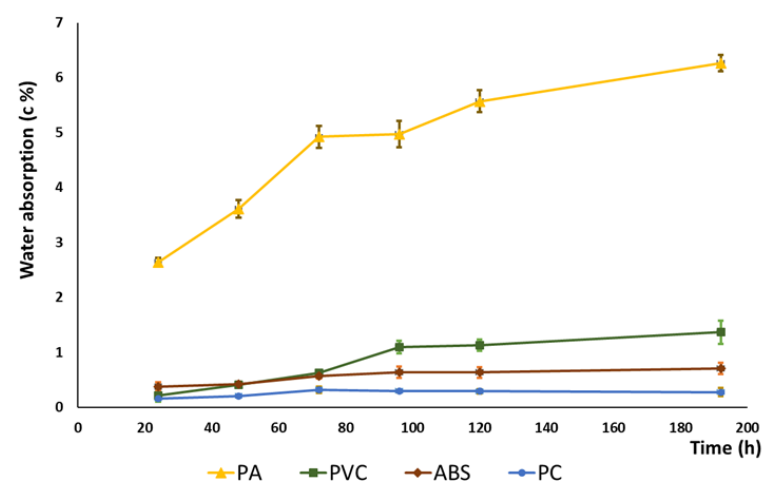

Figure 3. Water absorption of analyzed waste plastic samples: $\triangle-\mathrm{PA}$ - - PVC; - $\mathrm{ABS} ; \bullet-\mathrm{PC}$ 


\subsection{Separation performance of plastics}

\subsubsection{Separation performance of $P V C$ and $A B S$ through} flotation test modulated by $\mathrm{CaCl}_{2}$ solution

The mixtures of PVC and ABS in flotation tests consist of $10 \mathrm{~g}$ of each plastic type of similar size. Figure $4 \mathrm{a}$ shows that the recovery of PVC was over $98 \%$ regardless of the concentration of the $\mathrm{CaCl}_{2}$ solution used for flotation. The highest recovery rate for PVC was $99.75 \%$ determined when a $30 \% \mathrm{CaCl}_{2}$ solution was used. Regarding the recovery of ABS, it can be seen that the percentage of recovered ABS increases with the increasing concentration of $\mathrm{CaCl}_{2}$ solution. $94 \%$ is the highest recovery rate for $\mathrm{ABS}$, when $30 \% \mathrm{CaCl}_{2}$ solution was used for flotation. Results illustrated in Figure 4b indicate that the values of the ABS purity are higher than the values obtained for the $\mathrm{PVC}$, regardless of the $\mathrm{CaCl}_{2}$ solution concentration. Also, it can be observed that the higher values of PVC (93.72\%) and ABS (99.76\%) purity were obtained for the flotation tests when $30 \%$ $\mathrm{CaCl}_{2}$ solution was used.

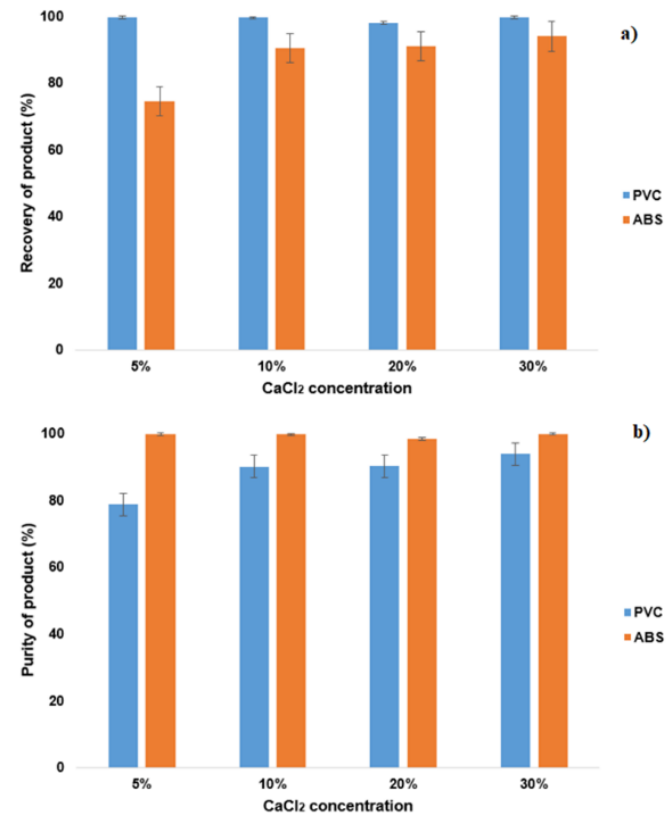

Figure 4. Effect of $\mathrm{CaCl}_{2}$ concentration on the a) recovery and $b$ ) purity of PVC and ABS plastics

3.2.2. Separation performance of $P V C$ and $P C$ through flotation test modulated by $\mathrm{CaCl}_{2}$ solution

Mixtures of $10 \mathrm{~g}$ of each plastic type (PVC and PC) were used in the flotation tests. It was observed that the higher recovery rate of PVC (99\%) was obtained after the flotation test with $10 \% \mathrm{CaCl}_{2}$ solution, while the lowest $(90 \%)$ was registered after the flotation test of PVC and PC mixture with $30 \% \mathrm{CaCl}_{2}$ solution (Figure 5a). Recovery rate of PC increased with the increasing of the $\mathrm{CaCl}_{2}$ solution concentration, from $27.23 \%$ when $5 \%$ solution of $\mathrm{CaCl}_{2}$ was used for flotation test to $97.62 \%$ when $30 \%$ solution of $\mathrm{CaCl}_{2}$ was considered (Figure 5a). The values for the PC purity determined were between 91 and $98 \%$, and the higher value was obtained when $10 \%$ solution of $\mathrm{CaCl}_{2}$ was used for flotation (Figure $5 b)$. Instead, the purity rate of PVC increased with increasing of the $\mathrm{CaCl}_{2}$ solution concentration and the higher value (97.51\%) was obtained when $30 \%$ solution of $\mathrm{CaCl}_{2}$ was used for the flotation test (Figure $5 \mathrm{~b}$ ).

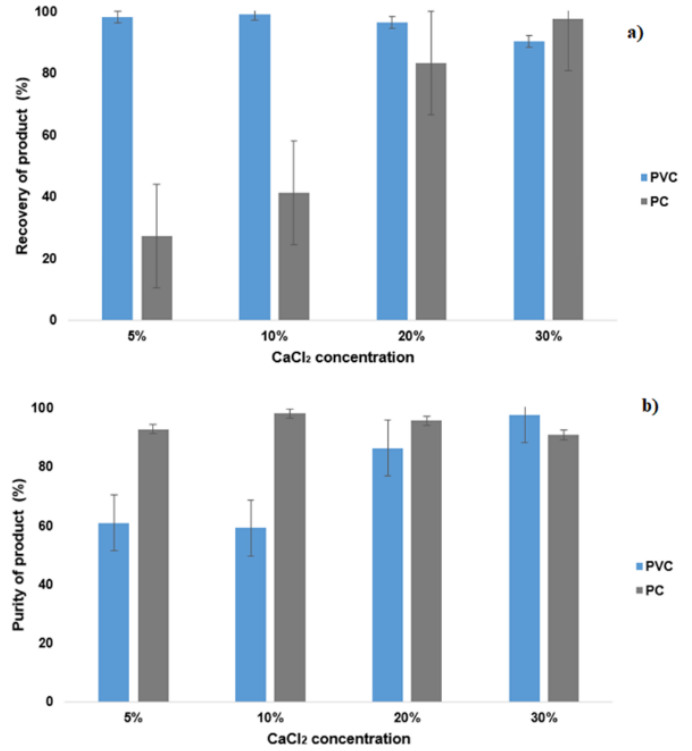

Figure 5. Effect of $\mathrm{CaCl}_{2}$ concentration on the a) recovery and b) purity of PVC and PC plastics

3.3. Separation performance of $P V C$ and $P A$ through flotation test modulated by $\mathrm{CaCl}_{2}$ solution

$\mathrm{PVC}$ and PA mixtures consisting of $10 \mathrm{~g}$ from each type of plastic were subjected to flotation tests. After weighing the samples, the degree of recovery and purity of PVC and PA were calculated. The obtained results showed that PA recovery rate increase, while PVC recovery rate decreases slightly with increasing of $\mathrm{CaCl}_{2}$ solution concentration (Figure 6a). PA recovery had the highest value $(95.25 \%)$ and the lowest value $(19.09 \%)$ when solutions of $30 \%$ and $5 \% \mathrm{CaCl}_{2}$, respectively, were used. The purity of PVC increased with the increasing concentration of $\mathrm{CaCl}_{2}$ solution (Figure 6b), this was observed also in the other flotation tests presented in this study. PA purity had high values between 96.70 and $98.97 \%$, the higher value was obtained when $\mathrm{CaCl}_{2}$ solution had a concentration of $10 \%$.

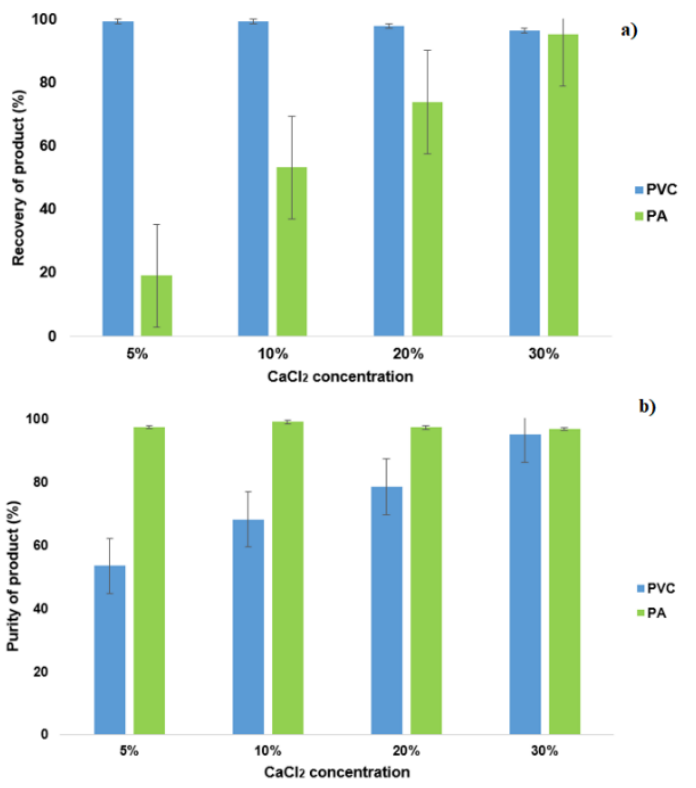

Figure 6. Effect of $\mathrm{CaCl}_{2}$ concentration on the recovery and purity of PVC and PA plastics 
Results indicated that after flotation tests the recovery rate of PVC decreases slightly with increasing of $\mathrm{CaCl}_{2}$ solution concentration and density, while the degree of recovery of other plastic types (ABS, PC, PA) increases significantly. The decrease in the recovery rate of PVC when using a $30 \% \mathrm{CaCl}_{2}$ solution can be explained by the fact that the density of the solution is close to the density of PVC. In terms of purity, it has been observed that purity rate of PVC increases with increasing concentration of $\mathrm{CaCl}_{2}$ solution and density, while the purity degree of other plastic types (ABS, PC, PA) decreases slightly. $\mathrm{CaCl}_{2}$ influences the wettability of plastic which increases with $\mathrm{CaCl}_{2}$ solution concentration. According to Pongstabodee et al. [13], $\mathrm{Ca}^{2+}$ contributes for neutralization of the plastics negative surface charges.

The flow chart of plastic separation through flotation is illustrated in Figure 7. After flotation, PVC submerged, while ABS, PC, and PA are floating. The same aspect was presented by Pongstabodee et al. [13] regarding the submersion of $\mathrm{PVC}$ and the flotation of ABS in $\mathrm{CaCl}_{2}$ solution. All types of plastic were weighed before and after flotation. They were washed and dried and then weighed after flotation.

The Pearson correlation analysis performed on the results of $\mathrm{CaCl}_{2}$ solution used in flotation tests and on the productivity of the separation process showed a strong negative correlation between density, electrical conductivity refractive index, concentration and the recovery values of PVC from the PVC - PA mixture ( $\mathrm{r}$ $=-0.982, r=-0.981, r=-0.906, r=-0.982$ ); while the purity results were positively influenced by the same parameters $(r=0.986, r=0.987, r=0.968, r=0.986)$. In the case of the PVC - PC mixture the results of PC recovery and the results of the PVC purity were positively influenced by density $(r=0.969, r=0.959)$, electrical conductivity $(r=0.983, r=0.952)$, refractive index $(r=0.976, r=0.964)$, and concentration $(r=$ $0.980, r=0.966)$ of flotation solution.

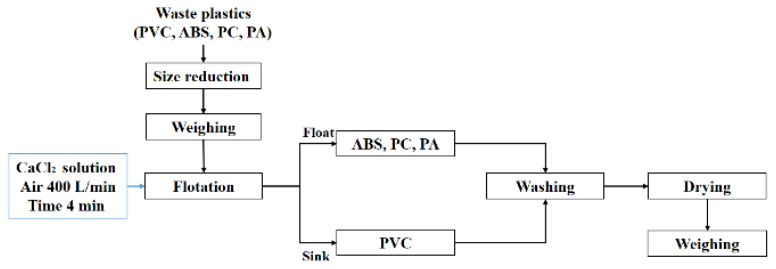

Figure 7. Flow chart of plastic separation through flotation

\section{Conclusions}

Forced aeration flotation was used successfully for plastic waste separation, being a promising method for plastic recycling resulted from electrical products. Both recovery and purity indicators were influences significantly by the concentration of flotation solutions. The highest recovery rate was obtained for the PVC samples $(99.75 \%)$ in the PVC - ABS mixture, while the highest purity was recorded for ABS samples (99.76\%) for the same mixture (PVC - ABS) and the same concentration of $30 \% \mathrm{CaCl}_{2}$. In the case of the PVC $\mathrm{PA}$ and PVC - PC mixtures, the PVC recovery is not significantly influenced by the concentration of the flotation solutions, whereas the PA and PC recovery are positively influenced by the increasing concentration of the flotation solutions.

\section{Conflict of interest}

Authors declare no conflict of interest.

\section{Acknowledgments}

The authors would like to thank the ECO Recycling CNE, Timisoara and Hidroplasto, Botosani for the supply of plastic waste.

\section{References}

[1]. E.D. Comanita, R. Hlihor, C. Ghinea, M. Gavrilescu, Occurrence of plastic waste in the environment: ecological and health risks, Environmental Engineering and Management Journal 15 (2016) 675-685.

[2]. H. Wang, C.Q. Wang, J.G. Fu, Floatability of polymer materials modulated by frothers, Waste Management 33 (2013) 2623-2631.

[3]. Plastics Europe, Plastics — the facts 2020. An analysis of European plastics production, demand and waste data (2020) Online at: https://www.plasticseurope.org/application/files/8 016/1125/2189/AF_Plastics_the_facts-WEB2020-ING_FINAL.pdf.

[4]. E.D. Comanita, C. Ghinea, M. Roşca, I.M. Simion, M. Petraru, M. Gavrilescu, Environmental impacts of polyvinyl chloride (PVC) production process, E-Health and Bioengineering Conference (EHB) (2015) $1-4$.

[5]. E.D. Comanita, C. Ghinea, R. Hlihor, M.I. Simion, C. Smaranda, L. Favier, M. Rosca, I. Gostin, M. Gavrilescu, Challenges and oportunities in green plastics: An assessment using the ELECTRE decision-aid method, Environmental Engineering and Management Journal 14 (2015) 689-702.

[6]. B. Ruj, V. Pandey, P. Jash, V.K. Srivastava, Sorting of plastic waste for effective recycling, International Journal of Applied Sciences and Engineering Research 4 (2015) 564- 571.

[7]. L.K. Ncube, A.U. Ude, E.N. Ogunmuyiwa, R. Zulkifli, I.N. Beas, An Overview of Plastic Waste Generation and Management in Food Packaging Industries, Recycling 6 (2021) 12.

[8]. N. Singh, D. Hui, R.. Singh, I.P.S Ahuja, L. Feo, F. Fraternali, Recycling of plastic solid waste: A state of art review and future applications, Composites Part B: Engineering 115 (2017) 409422.

[9]. S.M. Al-Salem, P. Lettieri, J. Baeyens, Recycling and recovery routes of plastic solid waste (PSW): A review, Waste Management 29 (2009) 26252643.

[10]. K. Ragaert, L. Delva, K. Van Geem, Mechanical and chemical recycling of solid plastic waste, Waste Management 69 (2017) 24-58.

[11]. C.Q. Wang, H. Fu, J.G. Wang, Y.N. Liu, Flotation separation of waste plastics for recycling-a review, Waste Management 41 (2015) 28-38. 
[12]. F. Pita, A. Castilho, Separation of plastics by froth flotation. The role of size, shape and density of the particles, Waste Management 60 (2017) 91-99.

[13]. S. Pongstabodee, N. Kunachitpimol, S. Damronglerd, Combination of three-stage sinkfloat method and selective flotation technique for separation of mixed post-consumer plastic waste, Waste Management 28 (2008) 475-483.

[14]. S.K. Utimura, A.P. Chaves, J.A. Soares Tenório, D.C. Romano Espinosa, Selecting chemicals for separation of ABS and HIPS in WEEE by froth flotation, Polímeros 29 (2019) 1-4.

[15]. F. Burat, A. Güney, M. Olgaç Kangal, Selective separation of virgin and post-consumer polymers (PET and PVC) by flotation method, Waste Management 29 (2009) 1807-1813.

[16]. C.Q. Wang, H. Wang, Y.N. Liu, Separation of polyethylene terephthalate from municipal waste plastics by froth flotation for recycling industry, Waste Management 35 (2015) 42-47.

[17]. F. Pita, A. Castilho, Separation of PET from other plastics by flotation combined with alkaline pretreatment, Polímeros: Ciência e Tecnologia 30 (2020) e2020026.

[18]. C.Q. Wang, H. Wang, G.H. Gu, Q.Q. Lin, L.L. Zhang, L.L Huang, J.Y. Zhao, Ammonia modification for flotation separation of polycarbonate and polystyrene waste plastics, Waste Management 51 (2016) 13-18.

[19]. C.Q. Wang, H. Wang, L.L. Huang, A novel process for separation of polycarbonate, polyvinyl chloride and polymethyl methacrylate waste plastics by froth flotation, Waste Management 65 (2017) 3-10.

[20]. Y. Zhong, H. Wang, J. Wang, Y. Zhang, K. Wang, C. Guo, S. Chen, M. Luo, Y. Du, L. Wang, Combination of sodium hypochlorite pretreatment and flotation towards separation of polycarbonate from waste plastic mixtures, Waste Management 99 (2019) 112-121.

[21]. Y. Zhang, C. Li, L. Wang, H. Wang, Application of froth flotation in the separation of polyvinyl chloride and polycarbonate for recycling of waste plastic based on a novel surface modification, Waste Management 110 (2020) 43-52.

[22]. ASTM Committee D-20 on Plastics, Standard test methods for density and specific gravity (relative density) of plastics by displacement, ASTM international (2008).

[23]. ISO 62:2008, Plastics - Determination of water absorption, (2008).

[24]. M. Viana, P. Jouannin, C. Pontier, D. Chulia, About pycnometric density measurements, Talanta 57 (2002) 583-593.

[25]. M. Luo, H. Jiang, Y. Zhang, H. Wang, Surface treatment with peroxymonosulfate for flotation separation of waste polyvinylchloride and acrylonitrile-butadiene-styrene: Optimization and mechanism, Journal of Cleaner Production 275 (2020) 124158.

[26]. J. Guo, X. Li, Y. Guo, J. Ruan, Q. Qiao, J. Bi, Y. Li, F Zhang, Research on flotation technique of separating PET from plastic packaging wastes, Procedia Environmental Sciences 31 (2016) 178184.

[27]. S.R. Mallampati, J.H. Heo, M.H. Park, Hybrid selective surface hydrophilization and froth flotation separation of hazardous chlorinated plastics from E-waste with novel nanoscale metallic calcium composite, Journal of Hazardous Materials 306 (2016) 13-23.

[28]. Omnexus, Density of Plastics: Technical Properties (2021) Online at: https://omnexus.specialchem.com/polymerproperties/properties/density.

[29]. UNEP, Converting Waste Plastics Into A Resource, United Nations Environmental Programme, International Environmental Technology Centre Osaka/Shiga (2009) pp. 32.

Received: 06.06.2021 Received in revised form: 20.07.2021 Accepted: 22.07.2021 